M. A. TAIROV, V. LEVCHENKO, I. A. STADNIY, Y. V. DMITRIV, S. O. DEHTIAROV,

M. O. KIBALNYI, A. V. MELNYK, S. Y. VESELOVYCH, Y. V. BORODULIN, S. V. KOLOTILOV, S. V. RYABUKHIN*, D. M. VOLOCHNYUK* (ENAMINE LTD., KYIV, TARAS SHEVCHENKO NATIONAL UNIVERSITY OF KYIV, AND NATIONAL ACADEMY OF SCIENCES OF UKRAINE, KYIV, UKRAINE)

Practical Synthetic Method for Functionalized 1-Methyl-3/5-(trifluoromethyl)-1H-pyrazoles

Org. Process Res. Dev. 2020, 24, 2619-2632, DOI: 10.1021/acs.oprd.0c00300.

\section{Regioselective Scalable Approaches to Trifluoromethylated Pyrazoles}

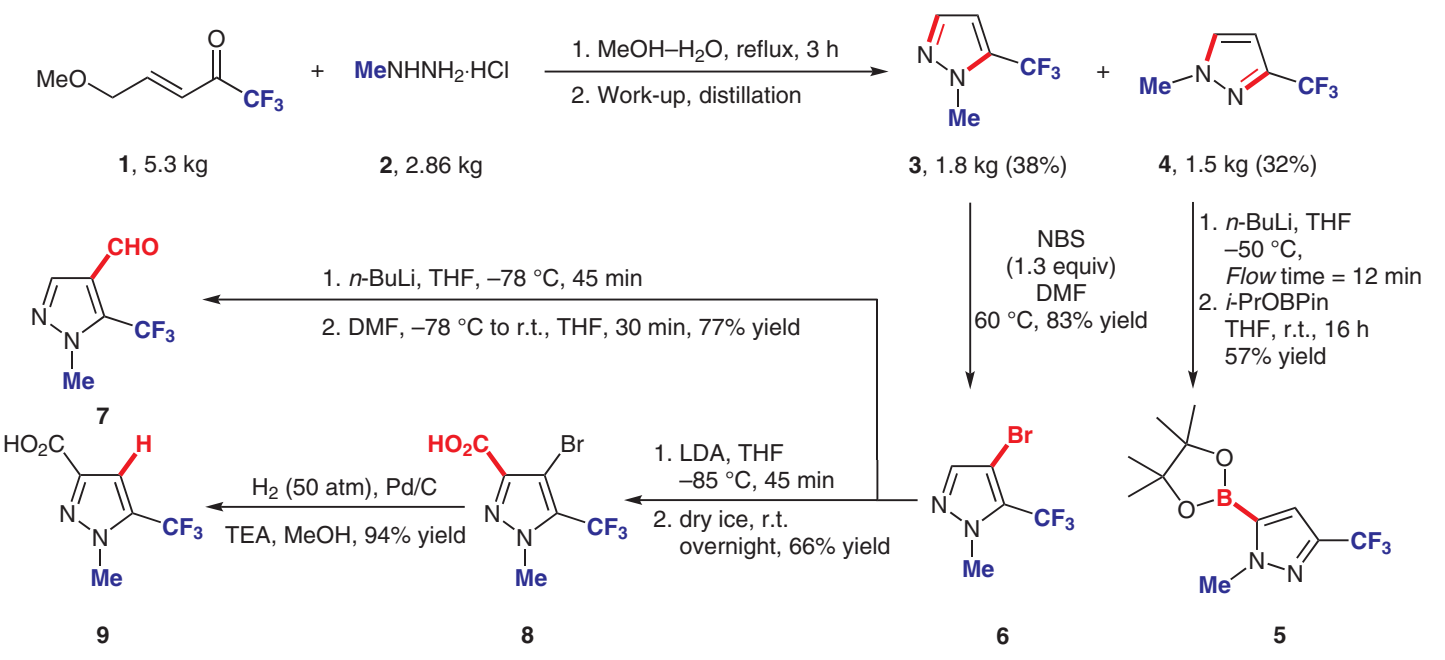

Significance: The regioselective scalable synthesis of 3/5-trifluoromethyl pyrazole derivatives represents an important challenge, given the prominence of these motifs in both agrochemicals and pharmaceuticals. The current report details a kilogram synthesis and efficient distillation-based separation of 1-methyl-(3-trifluoromethyl)-1H-pyrazole (4) and 1-methyl-(5-trifluoromethyl)-1H-pyrazole (3), and their subsequent regioselective elaboration in either batch or flow mode through a series of strategies based on lithiation/electrophilic trapping chemistries (M. Schlosser et al. Eur. J. Org. Chem. 2002, 2913).
Comment: Several approaches for the synthesis of the parent pyrazoles were evaluated, and the reaction of 4-ethoxy-1,1,1-trifluorobut-3-en-2-one (1) with methyl hydrazine hydrochloride (2) was scaled to provide access to the desired compounds. Functionalization of the 5-position was achieved by lithiation in flow followed by trapping in batch with a series of electrophiles (for example, $\mathbf{5}$ ). Judicious control of the concentration in flow proved important in avoiding precipitation. Bromination with NBS cleanly afforded the 4-bromopyrazoles $\mathbf{6}$, which could be subsequently elaborated either through halogen-metal exchange followed by functionalization (see 7) or by direct ortho-lithiation, functionalization, and debromination (for example, 9), although in the latter sequence control of temperature proved critical to avoid the formation of isomers through a 'halogen-dance' reaction (see Review below).

Review: M. Schnürch, M. Spina, A. F. Khan, M. D. Mihovilovic, P. Stanetty Chem. Soc. Rev. 2007, $36,1046-1057$

\section{Category}

Synthesis of Heterocycles

Key words

pyrazoles

trifluoromethylation

flow chemistry

lithiation

halogen-metal

exchange

direct orthometalation 